\title{
infâncias no campo: brinquedo, brincadeira e cultura
}

\author{
levindo diniz carvalho ${ }^{1}$ \\ universidade federal de minas gerais - brasil \\ rogério correia da silva ${ }^{2}$ \\ universidade federal de minas gerais - brasil
}

resumo

neste artigo, de contornos ensaísticos, busca-se discutir a brincadeira como prática cultural e sua presença nas infâncias vividas em contextos do campo ou das chamadas comunidades tradicionais no Brasil. No diálogo com os Estudos da Infância, pretende-se analisar as imagens que construímos sobre quem são essas crianças e o que suas brincadeiras informam sobre suas vidas e formas de sociabilidade. Analisaremos como artefatos culturais um pequeno repertório de brinquedos produzidos por crianças, problematizando as culturas infantis e suas formas de produção simbólica. Buscamos aqui, na relação com nossas experiências de pesquisa e formação de professores, apreender o significado cultural da brincadeira na tensão entre universalidade das formas e expressões da diversidade do brincar, produto do universo sócio-cultural onde se situa e ainda analisar os significados dessas experiências para as crianças. Ensaiamos ainda um pequeno diálogo com pesquisas que tiveram como foco as infâncias de diferentes povos do campo e suas contribuições para a compreensão da brincadeira como prática cultural. Por fim, aponta-se a dimensão do território como elemento central nos processos de apreensão do mundo, criação e participação da criança na cena social e anunciam-se desafios de pesquisa suscitados pela discussão aqui empreendida e que poderão instigar futuros exercícios de escrita.

palavras-chave: crianças; infâncias do campo; povos tradicionais; brincar; brincadeira.

resumen

\section{infancias en el campo: juguete, juegos y cultura}

En este artículo, de contornos ensayísticos, se busca discutir el juego como práctica cultural y su presencia en las infancias vividas en contextos del campo o de las llamadas comunidades tradicionales en Brasil. En el diálogo con los Estudios de la Infancia, se pretende analizar las imágenes que construimos respecto a quiénes son esos niños y sobre lo que los juegos informan sobre sus vidas y formas de sociabilidad. Analizaremos cómo artefactos culturales un pequeño repertorio de juguetes creados por niños del campo, problematizando las culturas infantiles y sus formas de producción simbólica. Buscamos aquí, en relación con nuestras experiencias de investigación y formación de profesores, aprehender el significado cultural del juego infantil en la tensión entre la universalidad de las formas y expresiones de la diversidad del jugar, producto del universo sociocultural en el que se sitúa, e incluso, analizar los significados de esas experiencias para los niños. Ensayamos todavía un pequeño diálogo con investigaciones que han tenido como enfoque las infancias de varios pueblos del campo y sus contribuciones para la comprensión del juego como práctica cultural. Finalmente, se señala la dimensión del territorio como elemento central en los procesos de aprehensión del mundo, creación y participación del niño en la escena social y se anuncian retos de

\footnotetext{
${ }^{1}$ E-mail: levindodinizc@gmail.com

2 E-mail: rogex.correia@gmail.com
} 
investigación planteados aquí por el debate entablado, que pueden venir a instigar futuros ejercicios de escritura.

palabras clave: niños; infancias del campo; pueblos tradicionales; jugar; juegos de niños.

\section{childhood in the countryside: toys, games and culture}

abstract

in this article, with an essay-like character, the authors seek to discuss children's games as cultural practices, regarding their presence in childhoods lived in rural contexts or in the so-called traditional communities in Brazil. Through a dialogue with "Childhood Studies", we intend to analyze the images we construct about who these children are as well as what their games tell us about their lives and forms of sociability. We will analyze a small repertoire of toys as being cultural artifacts produced by children, problematizing children's cultures and their forms of symbolic production. We seek here, in relation to our experiences of research and teaching training, an appreciation of the cultural meaning of games as lying between the universality of forms and the expressions of the diversity of playfullness, as a product of the sociocultural universe where they are located. In addition to this, we will try to interpret the meanings these experiences can have for children. We will also engage in a brief dialogue with the researches that focus on the childhoods in the countryside, analyzing their contributions to an understanding of playing as a cultural practice. Finally, the dimension of the territory for playing is pointed out as a central element in the processes of apprehension of the world, of creation and participation of the child in the social scene. Some challenges regarding research are aroused by the discussion undertaken here. We will argue that these challenges can instigate new writing exercises on this subject.

keywords: children; childhoods in the countryside; traditional communities; play games. 
infâncias no campo: brinquedo, brincadeira e cultura

\section{introdução}

Como compreender a experiência da brincadeira como um fenômeno cultural? De que forma é possível perceber a brincadeira e os aspectos sociais e humanos vividos pelas crianças quando brincam? E o que nos revelam as brincadeiras das crianças dos chamados povos campo e/ou comunidades tradicionais ${ }^{3}$ ?

Acreditamos que para introduzirmos o tema seja necessário assumirmos a forma como esta discussão sobre as brincadeiras das crianças do campo nos afeta. Somos professores e pesquisadores da cultura infantil e temos as crianças do campo como interlocutoras e seu repertório de brincadeiras como fonte de pesquisa. Neste sentido, as crianças do campo e pertencentes a povos tradicionais, suas experiências de infância e suas brincadeiras, são fortes referências em nosso imaginário e muitas vezes estruturam nossas ações em torno dos projetos de educação infantil, de infância e formação de professores.

Uma ideia basilar no movimento aqui proposto é a necessidade de rompermos com uma frequente idealização do campo como tipo ideal de vida, espaço que conformaria uma infância livre das asperezas do mundo (sobretudo como sinônimo de vida saudável, da valorização da liberdade e do contato direto da criança com a natureza) e fonte de brincadeiras que se diferenciam daquelas realizadas nos espaços urbanos.

Esta pequena confissão talvez sirva para que o leitor compreenda nosso grau de envolvimento com o tema e o desafio que nos colocamos aqui, que é o de identificar criticamente, o nosso lugar de adultos produtores de discursos sobre a criança do campo e suas brincadeiras, como bem problematiza Rosemberg (2013).

\footnotetext{
${ }^{3}$ Reconhecemos aqui a diversidade de infâncias Brasileiras nas crianças pertencentes aos Povos do campo e Comunidades Tradicionais: "grupos culturalmente diferenciados e que se reconhecem como tais, que possuem formas próprias de organização social, que ocupam e usam territórios e recursos naturais como condição para sua reprodução cultural, social, religiosa, ancestral e econômica, utilizando conhecimentos, inovações e práticas gerados e transmitidos pela tradição" (Decreto $\mathrm{n}^{\circ}$ 6.040, de 07 de fevereiro de 2007). Nesse texto busca-se, uma abordagem horizontal sobre diferentes realidades, lançando mão de uma pequena parte do repertório da cultura infantil nesses grupos e dialogando com pesquisadores da área afim de tematizar as relações entre brincadeira, brinquedo e cultura.
} 
Baseando-nos assim em nossa experiência como educadores e pesquisadores da área dos jogos e brincadeiras, neste texto optamos por um referencial teórico que chamaremos de "biográfico-fenomenológico e sócio-antropológico" da brincadeira. Ele é baseado em nossas trajetórias de vida e profissional, do contato direto com crianças de vários grupos culturais e em situação de brincadeiras quando registramos toda a singularidade e o aprendizado proporcionado por estas experiências nos marcando enquanto professores, pesquisadores e pessoas. Sem dúvida, nossa experiência com a pesquisas etnográficas junto a crianças em contextos urbanos e não urbanos ${ }^{4}$ e vivência por um longo período imersos no campo de nossos estudos (bairros da periferia de Belo Horizonte, escolas de Educação Infantil, escolas em contextos do campo e aldeias indígenas) nos oportunizaram conhecer as culturas infantis "de perto e de dentro". Por fim, os autores e teorias que hoje compõem os estudos sociais da infância (sociologia da infância e da antropologia da criança), constituem o enquadramento teórico com o qual buscamos dialogar.

Neste artigo, de contornos ensaísticos, buscaremos caracterizar e analisar as imagens que construímos sobre quem são essas crianças, e o que informam suas brincadeiras sobre suas vidas e formas de sociabilidade. Buscamos apreender o significado cultural da brincadeira na tensão entre universalidade das formas e expressões do brincar e sua diversidade, produto do universo sócio-cultural onde se situa. Ensaiamos ainda um pequeno diálogo com pesquisas que tiveram como foco as infâncias de diferentes povos do campo e suas contribuições para a compreensão da brincadeira como prática cultural. Por fim, anunciamos alguns desafios para a pesquisa nesse campo que poderão instigar futuros exercícios de escrita.

\footnotetext{
${ }^{4}$ Nesse sentido sugerimos indicamos nossos trabalhos Carvalho (2005) uma pesquisa com a infância e brincadeiras vividas por crianças em uma aldeia indígena Pataxó e por crianças da periferia de Belo Horizonte. E Silva (2014) um estudo a infância vivida por meninos indígenas Xakriabá, sua circulação pelo território, sua participação e aprendizado nas tarefas diárias do grupo.
} 


\section{brinquedos e brincadeiras do campo e seus aspectos socioculturais}

Quem já teve a oportunidade de viajar pelo interior de nosso país, se atento às culturas infantis, foi capaz de constatar que a infância vivida pelas crianças do campo é tão rica quanto também diversa. Comunidades ribeirinhas e caiçaras, quilombolas, ciganas ou indígenas; das regiões do cerrado ou do sertão, do pantanal ou da floresta amazônica: são mais de 25 diferentes denominações e grupos reconhecidos legalmente na sua especificidade e cultura ${ }^{5}$. Mas o que dizer do repertório de brinquedos e brincadeiras produzidos por essas crianças?

Capturamos nas brincadeiras realizadas por esses grupos elementos essenciais como a inventividade e criatividade na produção dos brinquedos, um traço estético peculiar e uma dimensão poética presente nos gestos e movimentos e seu papel no fortalecimento dos vínculos sociais. Em suas brincadeiras percebemos uma forte conexão e um simultâneo enraizamento das crianças à natureza e às culturas de seus grupos sociais.

Nesses contextos, um aspecto que vale a pena considerar diz respeito a ideia de que o brincar não é uma exclusividade dos grupos infantis. Em muitos casos, adultos e crianças partilham momentos de brincadeiras. Esta constatação reflete uma distância das infâncias do campo daquelas vividas nos centros urbanos no que diz respeito a uma cisão entre os mundos do adulto e infantil. Longe de ser uma demarcação forte e rígida encontramos um compartilhamento maior de experiências entre adultos e crianças, como por exemplo, no trabalho na roça, nas festividades e cerimônias religiosas. Ainda assim, este compartilhamento de experiências não exclui a especificidade geracional expressa e um ponto de vista das produções infantis.

Em outra chave de análise ao adentrarmos na discussão dos jogos, brinquedos e brincadeiras de crianças do campo, quase sempre somos levados a considerar o campo como local de preservação daquilo que classificamos como

\footnotetext{
${ }^{5}$ As denominadas comunidades ou povos tradicionais os Indígenas, Quilombolas, Seringueiros, Castanheiros, Quebradeiras de coco de babaçu, Comunidades de fundo de Pasto, Faxinalenses, Pescadores artesanais, Marisqueiras, Ribeirinhos, Varjeiros, Caiçaras, Praieiros, Sertanejos, Jangadeiros, Ciganos Açorianos, Campeiros, Vazanteiros, Pantaneiros, Geraizeiros, Veredeiros, Caatingueiros, Retireiros do Araguaia dentre outros.
} 
brincadeiras ou jogos tradicionais ${ }^{6}$ como as brincadeiras de roda, o pião, a pipa, as cinco-marias, considerados como "patrimônio cultural humano".

Existem várias hipóteses que indicam a força desta ideia. Talvez seja por influência e contribuição dos pesquisadores folcloristas ${ }^{7}$ brasileiros que se dedicaram parte de seus estudos aos jogos e brincadeiras infantis como Luis Câmara Cascudo (1988), Nicanor Miranda (1984), Florestan Fernandes (2004[1944]), Veríssimo de Melo (1985), desde a primeira metade do século XX. O período registrado em seus trabalhos representou os jogos e brincadeiras de um país predominantemente rural, mas que vivia processos de grandes mudanças iniciadas pela industrialização e reformas fundiárias que levaram ao êxodo rural e ao crescimento das grandes cidades.

Mais recentemente destacamos as produções como as de Kishimoto (1999) e Friedman (1990) com importante entrada no campo da educação e na formação de professores, trabalhos de relevância como os de Amado (2002) que organiza um inventário dos chamados brinquedos populares, e de Carvalho et al (2003) que divulga um coletânea de pesquisa sobre as brincadeiras de crianças brasileiras em diferentes grupos culturais e ainda a preciosa pesquisa de Lydia Hortélio acerca da música na cultura infantil. Esse conjunto de produções aponta tanto para compreensão do repertório de brinquedos e brincadeiras como um patrimônio da cultura infantil como para uma educação das crianças centrada na linguagem do brincar e da necessidade premente da escuta das crianças.

Também constatamos a presença desta ideia em importantes projetos e registros de produções videográficas brasileiras $^{8}$ nos últimos anos enfocando, sobretudo os brinquedos e brincadeiras das crianças do campo e, por fim, nos projetos pedagógicos desenvolvidos nas escolas cujo objetivo é valorizar as chamadas brincadeiras tradicionais infantis.

\footnotetext{
${ }^{6}$ Em sua definição mais corrente, chamamos de jogo tradicional infantil aquele conjunto de práticas lúdicas infantis que conservam as seguintes características: "anonimato, tradicionalidade, transmissão oral, conservação, mudança e universalidade" (KISHIMOTO, 1993, p. 29).

${ }^{7}$ Nos estudos dos autores denominados folcloristas expressões do que hoje denominamos culturas infantis eram consideradas como manifestações da cultura popular mais ampla.

${ }^{8}$ Como é o caso do Documentário Territórios do Brincar (2015) com direção de Renata Meireles e David Reenks e do filme Tarja Branca (2014) com direção de Cacau Rhoden.
} 
Um aspecto que gostaríamos dar a atenção é o fato de vários autores que estudam o tema afirmarem é que muitas vezes essas brincadeiras ganharam a dimensão de "entidades", sem quaisquer vínculos com seus respectivos contextos sociais e assim sendo colocados acima dos sujeitos que brincavam. Esta forma de abordar a cultura feita pelos folcloristas foi muito problematizada por Florestan Fernandes ainda nos anos 40 do século passado, quando criticou a maneira de abordar os elementos da cultura dissociando-os do contexto e principalmente do grupo social que os produziu. Nas palavras de Roger Bastide - professor à época de Florestan e que prefacia a sua obra "As trocinhas do Bom Retiro" -, não se pode estudar a brincadeira esquecendo-se da criança que brinca.

Outro fenômeno também nos intriga nessas pesquisas é que, do ponto de vista da antropologia, ao analisarmos as concepções de cultura inerentes nestes trabalhos, surpreendentemente, as teorias sobre os jogos tradicionais conseguem ao mesmo tempo acolher os princípios antropológicos do relativismo cultural (que apelam para as singularidades e diversidades dos povos e a incomparabilidade entre os mesmos) mas, ao reconhecerem a recorrência destas brincadeiras presentes em várias culturas, caminham para propostas mais estruturalistas de análise (quando apelam para seu caráter universal e presente em todas as culturas).

Estas ideias de identidade e de universalidade podem parecer à primeira vista contraditórias, mas estiveram (e ainda permanecem presentes), muitas vezes indo na contramão da ideia de diversidade cultural dos povos do campo que salientamos anteriormente. $\mathrm{O}$ conceito de identidade reflete uma concepção de cultura que emerge na origem da disciplina antropologia, ainda na Alemanha, cuja definição trazia a ideia da cultura como o espírito ou identidade nacional de um povo. Desta forma, a pesquisa dos folcloristas, ao identificarem a presença de uma mesma brincadeira em várias regiões do país (com pequenas variações) só reforçava a ideia de ser a brincadeira um forte elemento identitário da cultura popular brasileira.

$\mathrm{Na}$ ênfase da dimensão tradicional das brincadeiras (sobretudo por se contrapor ao "progresso da cultura") encontramos ainda a ideia de definir as 
brincadeiras infantis como "sobrevivências" (FERNANDES, 20049), pois elas preservam ou fazem referência a práticas sociais que pertenceram ao mundo adulto de períodos históricos anteriores (como no exemplo das brincadeiras de roda criadas a partir dos folhetins novelescos ou as danças de salão da sociedade adulta de séculos passados).

Foram estas questões apresentadas por Friedmann (1990, p. 97) quando destaca que "É interessante observar a existência de certos padrões lúdicos universais, mesmo com diferenças regionais, variações na designação ou na existência ou supressão de certas regras". Algumas práticas culturais da infância, portanto, ultrapassam os limites de inserção cultural, temporal e geográfica dos grupos infantis. Como analisar essa recorrência no tempo e no espaço? As crianças partilham rituais, brincadeiras e jogos, que são transmitidos entre as gerações, isso explica a permanência de brinquedos como o pião em uma época de tantos jogos eletrônicos. A brincadeira é, portanto, transmitida entre o próprio grupo de crianças e também pelos adultos.

Entretanto a ideia que predomina na noção de brincadeiras tradicionais extrapola a sua associação a identidade de um povo ou a ideia de diversidade cultural dos povos que as praticam. As brincadeiras tradicionais apresentam um caráter universal presentes em muitas culturas. Neste sentido, a ideia da universalidade das brincadeiras serviu de explicação e apoio a várias abordagens teóricas da antropologia como, por exemplo, os estudos evolucionistas de caráter eminentemente etnocêntricos (quando estabeleceram hierarquias entre os diferentes grupos culturais por identificarem determinadas práticas de jogos como elementos que situariam determinadas sociedades em etapas diferentes de uma mesma linha de evolução) ou mesmo a estudos que procuravam uma explicação para a presença de uma mesma brincadeira em vários locais e grupos diferentes, o

\footnotetext{
${ }^{9}$ Reconhecemos aqui a forte alusão ao termo cunhado pelo antropólogo Edwart B. Tylor: “Processos, costumes, opiniões, etc., que foram transportados pela força do hábito para um novo estado da sociedade diferente daquele em que se tinham organizado e, que, desta forma permanecem como provas e exemplo de uma condição cultural mais antiga de onde a mais nova se desenvolveu". (Tylor em Primitive Culture, 1913, vol.i, p.16, citado por MAIR 1985, p.31).
} 
chamado difusionismo cultural $^{10}$, ambas perspectivas bastante criticadas atualmente $^{11}$. Por fim, para caracterizar este rápido panorama, podemos citar estudos da cultura e personalidade (MEAD 1928, BENEDICT 2007) que buscaram a significação do jogo na cultura destacando sua importância como um sistema projetivo similar à arte ou à religião. Neste sentido os jogos seriam definidos como geradores e expressão da personalidade e da cultura de um determinado grupo cultural.

Podemos afirmar que a associação entre brincadeiras tradicionais e infâncias do campo possui muitos limites. Primeiramente porque a ideia das brincadeiras tradicionais não pode ser contida pela ideia de infância do campo e vice-versa e na definição mesma destes jogos sua intenção seria não se prender a único grupo, local ou época. Em segundo lugar, porque, pelas criticas apresentadas acima, a compreensão de brincadeiras tradicionais não abarca as especificidades culturais de cada grupo do campo.

É importante dizer ainda que as palavras popular e tradicional embora utilizadas como sinônimas traduzem elementos diferentes no campo da cultura. A título de exemplo podemos citar a confusão que pode gerar hoje utilizar, a expressão brincadeiras tradicionais, pois poderia ser associada à produção das comunidades tradicionais, ou seja, de parte considerável (mas não todos) de povos do campo como populações indígenas, comunidades quilombolas, caiçaras, pomeranas, ciganas entre outras. São populações detentoras de conhecimentos tradicionais que não somente se refere à noção de um patrimônio cultural coletivo, compartilhado e em constante movimento, como também a "conjuntos duradouros de formas particulares de gerar conhecimentos" (CUNHA, 2009, p. 364). Neste sentido, as formas particulares de gerar conhecimento contrapõem-se à universalidade apregoada pela noção de brincadeiras tradicionais.

\footnotetext{
${ }^{10}$ Os jogos foram difundidos através das trocas provenientes dos contatos entre diferentes povos eles teriam um local de origem e se propagariam por meio da difusão, migração, apropriação, aculturação ou assimilação, para depois adquirir conotações locais.

${ }_{11}$ Lembramos aqui que as criticas feitas a ambas perspectivas no que diz respeito ao uso de paradigmas diacrônicos nos estudos comparativos entre elementos de diferentes culturas, sem qualquer provas históricas, arqueológicas e etnográficas levou tais especulações ao descrédito pelo campo da antropologia.
} 
Ainda assim, na ausência de uma teoria que resolva a questão optamos por apresentar autores que insistem numa terceira via ao considerar a universalidade e idiossincrasia como faces de um mesmo objeto. Speber (1978, apud CARVALHO et al, 2003), afirma que “a brincadeira apresenta a tensão entre idiossincrasia e universalidade" que caracteriza outros universais culturais definidos pela antropologia, tais como as regras de casamento, rituais de saudação, receitas culinárias, etc. Para este autor, alguns dos brinquedos e brincadeiras possuem relativa recorrência temporal e espacial, ao mesmo tempo em que recebem características próprias, se transformam ao longo da história da humanidade. São constituídos e reconstituídos como tradições culturalmente transmitidas. Nessa dinâmica, algumas brincadeiras desaparecem, outras vão sendo modificadas e outras permanecem. Essa permanência, segundo Carvalho et al (2003, p 19), “tende a correlacionar-se com o grau de ritualização e estereotipa das brincadeiras". Segundo os autores, os procedimentos de sorteio na brincadeira de pegador ou rimas em brincadeiras de roda, por exemplo, são mais permanentes.

Para concluir, na busca de uma definição de jogos e brincadeiras, numa perspectiva mais fenomenológica e estética da experiência do brincar - adotando a perspectiva sugerida por Huizinga (2014) de ver o brincar de dentro -, podemos dizer que as brincadeiras conectam-nos, e também às crianças, com: a história do lugar, as histórias dos seus pais e avós, e ainda com as pessoas anônimas que deixaram para as gerações futuras este patrimônio. As brincadeiras trazem a vida condensada em micro-universos. Elas nos narram histórias, são uma forma de registro de tempos e épocas passadas. Esta memória das experiências passadas vividas por outras gerações está registrada, por exemplo, nas letras e nas músicas das brincadeiras de roda e de versos, na harmonia dos movimentos, nos seus gestos expressivos. A brincadeira é neste sentido memória e linguagem, pois, ao brincarmos tomamos contato com esta história e a produzimos. Não uma história de heróis, de seus feitos e conquistas, de batalhas e guerras mas de pessoas anônimas que como cronistas registraram nas brincadeiras aquilo que temos de mais universal: a celebração da vida. Quando brincamos esse passado se faz 
presente em nós, entra em nosso corpo pela porta da fruição e nos marca, constrói nossas sensibilidades e assim as brincadeiras passam a fazer parte de nossa própria história (ou será que nós quando brincamos é que começamos a fazer parte da história do lugar?). Ao brincarmos vivemos a experiência de "arrebatamento". A brincadeira adquire então um sentido não real, não palpável ou empírico. A brincadeira nos arranca da rotina da inércia, da seriedade do mundo.

A brincadeira é um tempo dentro do tempo, nela temos a sensação de que ele foi encapsulado, é onde as coisas mudam de sentido e que as regras acordadas entre seus participantes são as que sustentam e mantém esta nova realidade, enquanto o jogo durar. O tempo da brincadeira não é o tempo da fábrica, muito menos o tempo da TV ou da escola. É o tempo do ócio, o tempo inútil, nãoprodutivo, não visa um fim ou um produto.

\section{o brinquedo como um artefato cultural e a criança que brinca}

As crianças compreendem o mundo na experiência da brincadeira e o fazem na interação com as outras crianças e com os adultos. Nessa interação a criança compreende o mundo, experimenta suas emoções e elabora suas experiências. As brincadeiras são para as crianças uma fonte de imagens e universos imaginários possíveis que ela manipula ao brincar ampliando e alargando suas experiências. Ao mesmo tempo as brincadeiras oferecem e sugerem formas de interação. Como podemos observar na foto abaixo de um registro de campo das crianças pataxó brincando de casinha. Várias ações cotidianas do universo social e cultural do povo Pataxó se desdobram nesta brincadeira como colheita, matar galinhas e cuidar dos filhos.

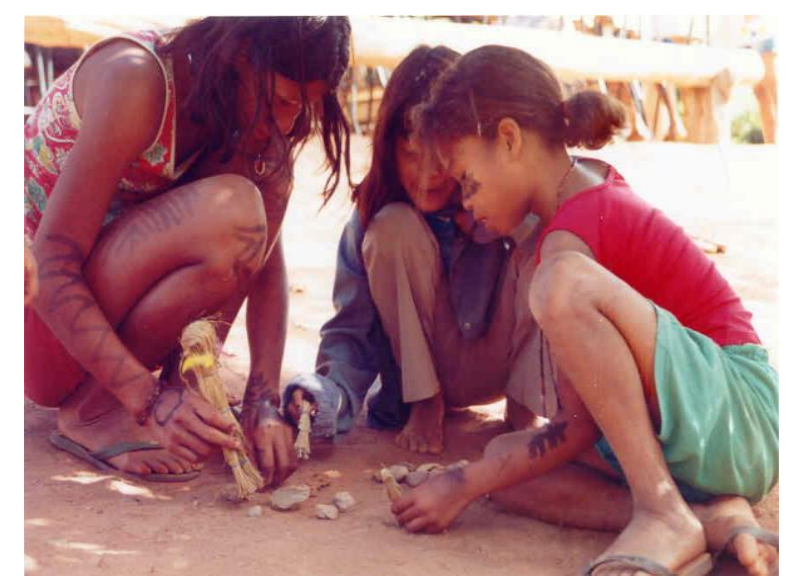

Imagem 1 : Brincadeiras de casinha. Reprodução da vida doméstica pataxó nas brincadeiras de asinha (colheita, matar galinha, cuidar dos filhos). Fonte: Acervo pessoal - 2014 
Os brinquedos e brincadeiras representam formas singulares de compreensão e apreensão do mundo pelas crianças. Alguns brinquedos são construídos em certos lugares, tanto pelos materiais disponíveis quanto pelo universo adulto com o qual crianças dialogam. A canoa feita de palha de coco e famílias de bonecas de palha, (registradas nas imagens a seguir) exprimem características.

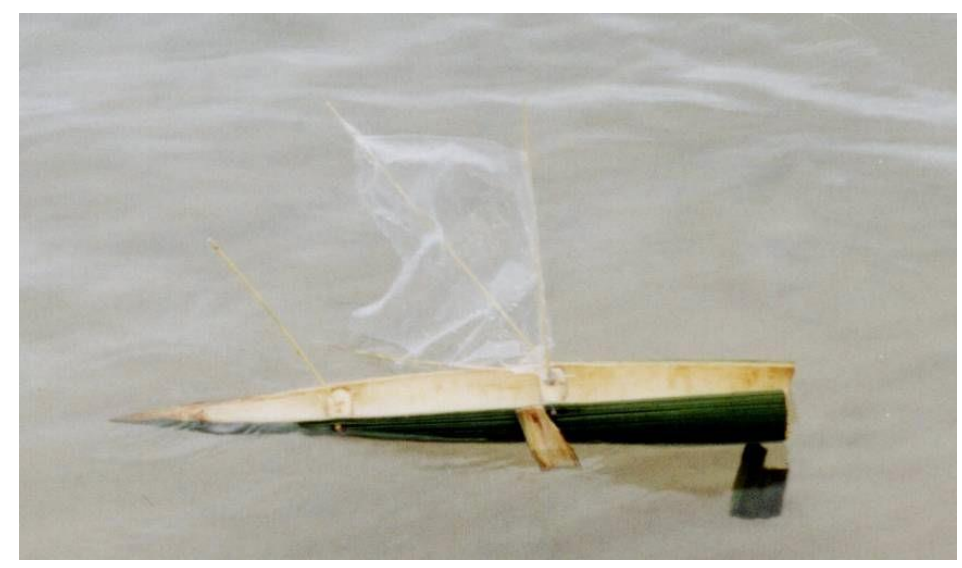

Imagem 2 : Canoa de casca de Pati Comunidade Caiçara - Mangue Seco - Bahia Fonte: Acervo pessoal - 2009

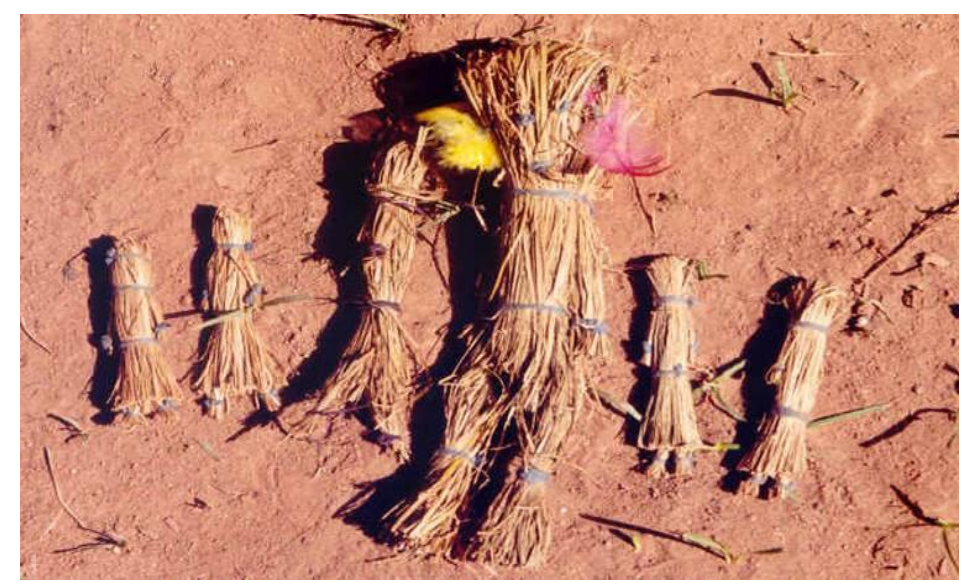

Imagem 3: Bonecas pataxós Fonte: Acervo pessoal - 2014

Tais brinquedos são, portanto, práticas singulares e próprias de determinados grupos de crianças exprimem ao mesmo tempo uma totalidade social e exemplificam como o universo adulto é referência para os elementos que compõem o patrimônio de brinquedos da cultura infantil. 
Como linguagem que liga as crianças à experiência social, a brincadeira atua como expressão e forma de significação do mundo. A brincadeira possibilita a exploração de lugares e de situações novas, além de permitir à criança a representação da realidade e a criação. Ao brincar, a criança ocupa lugares diferentes do seu e compreende sistemas simbólicos fundamentais a inserção do indivíduo na história e na cultura. Nesse sentido, a brincadeira é uma linguagem que significa cultura:

Brincar é visto como um mecanismo psicológico que garante ao sujeito manter certa distancia em relação ao real, fiel, na concepção de Freud, que vê no brincar o modelo do princípio de prazer oposto ao princípio de realidade. Brincar torna-se o arquétipo de toda atividade cultural que, como a arte, não se limita a uma relação simples com o real. (BROUGERE, 1998, p. 12).

Com os brinquedos as crianças muitas vezes experimentam a manipulação a produção de objetos e personagens que compõem o universo adulto, essa é a referência para as crianças em suas brincadeiras e suas ações são reproduzidas com um sentido próprio e essencial ao processo de apreensão do mundo. Temos nesses brinquedos produzidos pelas crianças uma referência que se assemelha mais a um exercício de uma metalinguagem, pois as crianças brincam com as leituras que outras crianças e adultos fizeram do mundo.

O brinquedo constitui um artefato dialógico que assume papéis dos mais diversos tipos, em razão do interesse e da curiosidade da criança. O brinquedo é um estímulo material que provoca, faz fluir o imaginário infantil.

[...] A simbologia deste instrumento de brincar atravessa a fronteira do físico em direção ao espiritual e faz dele instrumento que promove interação, diálogo, aproximação com o lúdico, reforço de habilidades cognitivas e de relação de sociabilidade. (SILVA, 2006, p. 108)

Os brinquedos lidam com o âmbito da reprodução da realidade da criança e seus contextos. Segundo Kishimoto (1999, p.24), o brinquedo, em sua forma e dimensão delicadas e antropomórficas, "metamorfoseia e fotografa [os diversos tipos de realidades], não reproduzindo apenas objetos, mas uma totalidade social". 

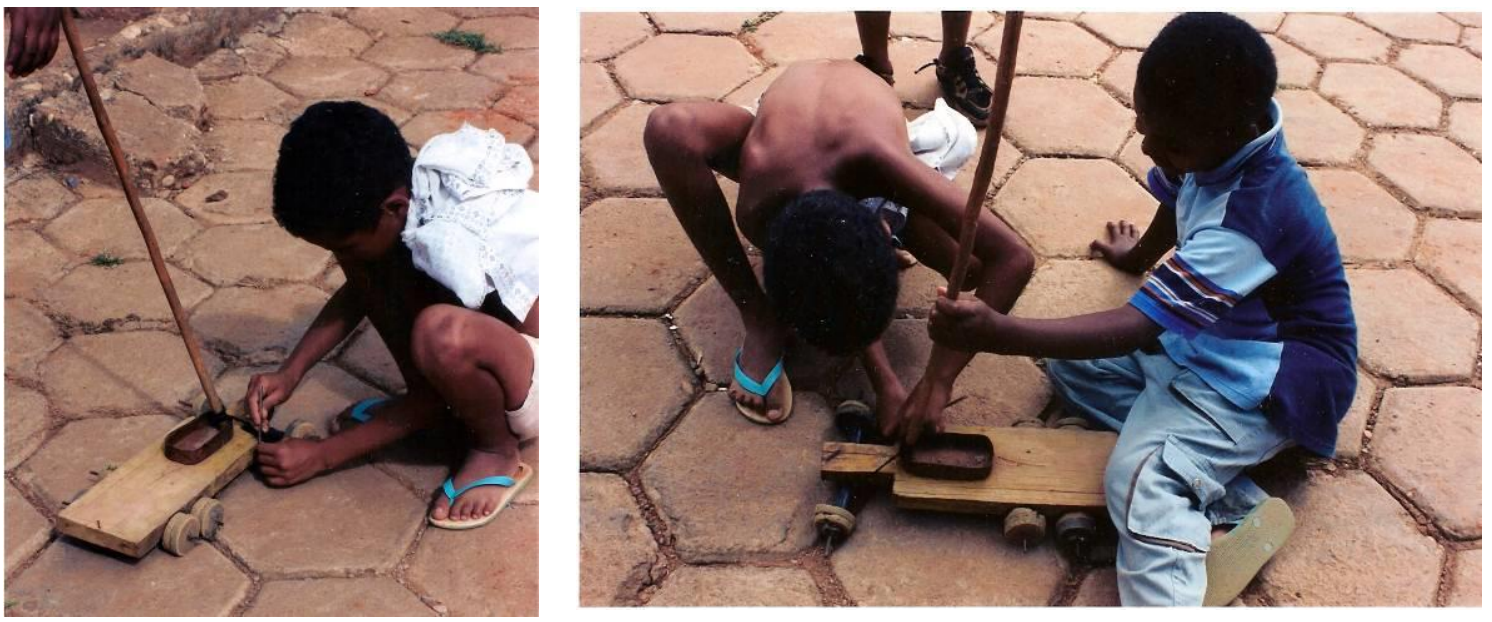

Imagem 4: Meninos construindo carrinho. Chapada do Norte-MG

Fonte: Acervo pessoal - 2006

Através das duas fotos acima, observamos o processo de construção de um carrinho tendo como construtores dois meninos de Chapada do Norte, Minas Gerais. Chama a atenção o fato de os meninos conseguirem reunir num único brinquedo elementos aparentemente tão díspares: lata de sardinha, madeira, borracha de chinelos, cabo de vassoura, tampa de cereal. Na tarefa de reproduzir o objeto de desejo, eles se deparam com intrincados e complexos mecanismo como a construção dos eixos das rodas e do sistema de direção (o carrinho é pilotado pelos meninos através de um "volante" de tamanho natural, conectado ao carro através de um cabo de vassoura). Utilizando esta experiência como exemplo, podemos dizer que na experiência em que o brinquedo é construído ${ }^{12}$, a criança, além de transformar a si própria, também exerce uma demiurgia sobre a matéria, gerando coisas que rolam, que mexem, que andam, que produzem sons, que adormecem, enfim, criva uma vida, não uma propriedade. (AMADO, 2002)

\footnotetext{
${ }^{12}$ Cabe ponderar, ainda, a existência de um vasto numero brinquedos produzidos para as crianças e não por elas, o que diferencia, em parte, seus usos e possibilidades: Na paulatina passagem de um modelo artesanal de produção para um modelo industrial, o brinquedo deixou de ser um produto de 'restos', cuja pluralidade de formas e materiais dava vazão ao subjetivo conteúdo imaginário da criança, para adquirir, então, um status de fabricação especializada, cuja representação poderia vir a predefinir ou sugerir a natureza da brincadeira. (ALMEIDA, 2006)
} 


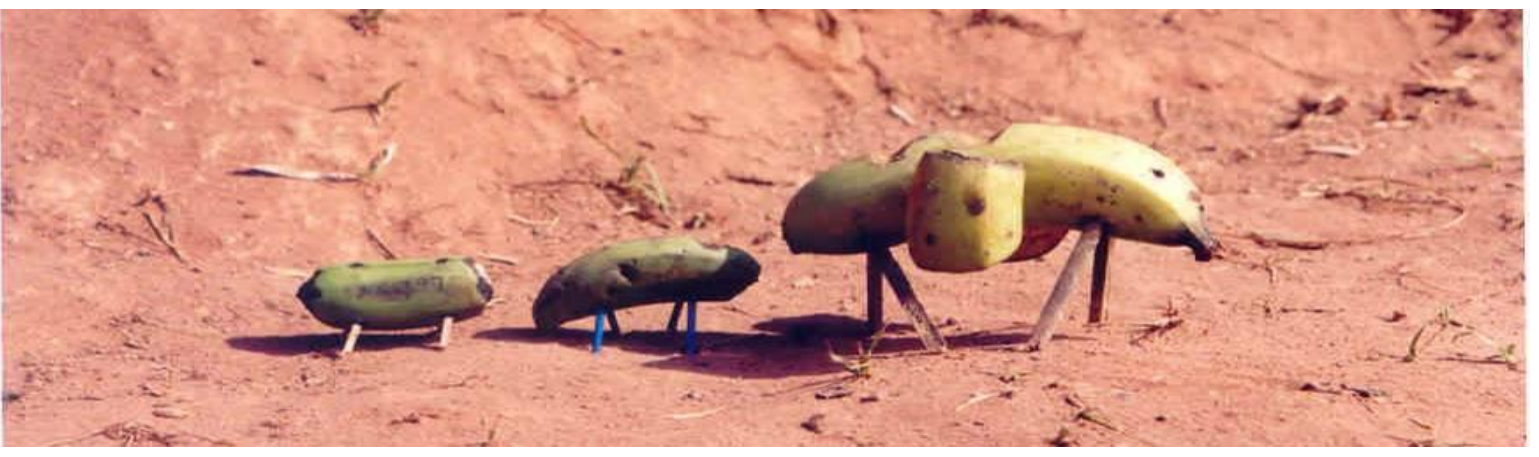

Imagem 5: Burrinhos de banana. Brinquedo pataxó.

Fonte: Acervo pessoal - 2014

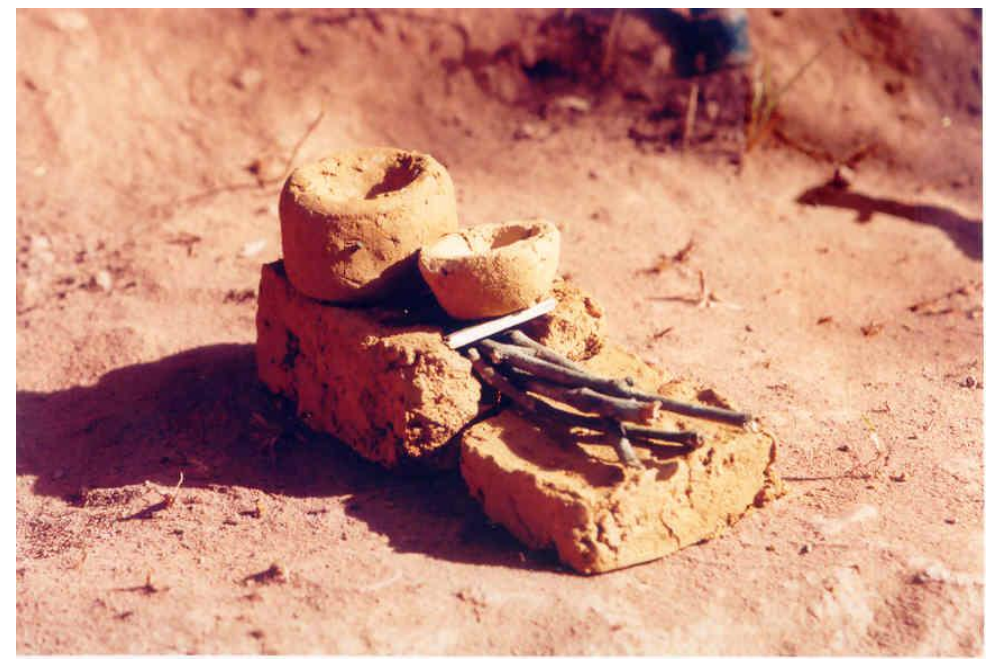

Imagem 6: Fogãozinho de barro. Araçuaí - Minas Gerais

Fonte: Acervo pessoal - 2014

O brinquedo estimula a representação, a expressão de imagens e situações que evocam aspectos da realidade, além de despertar em nós, adultos, um imaginário de infância, com representações veiculadas pela memória e imaginação.

\section{brincadeira, cultura e infâncias do e no campo}

A compressão tão fortemente presente no campo teórico de que a ideia de infância é uma construção social nos instiga a entender que essa construção está sujeita às transformações históricas e contextos geográficos, culturais e políticos. Portanto, ainda que se tenha contemporaneamente um entendimento de infância, existem múltiplas condições de se viver esse ciclo da vida, que varia em função das realidades socioculturais.

Em determinadas culturas as crianças ocupam uma maior centralidade e autonomia, como por exemplo, nas culturas indígenas teremos os jogos e brincadeiras como 
produtos destas condições. As crianças circulariam mais pelos espaços, teriam momentos de encontro com seus pares, os brinquedos e brincadeiras como fruto destes encontros que expressariam o resultado desta circulação e dos conhecimentos por elas adquiridos. Como no estudo desenvolvido por Angela Nunes (1999), que define que, ao estudar as brincadeiras das crianças Awê Xavante, conclui que as crianças indígenas desenvolvem noções de espaço e tempo a partir da sua livre circulação pelos espaços da aldeia e pelas brincadeiras neles realizadas. Em outro estudo desenvolvido também com crianças indígenas Galibi-Marworno, Camila Codonho (2007) afirma que as brincadeiras das crianças estão condicionadas à idéia de $h \tilde{a}$, que ao contrário do grupo estudado por Nunes tem um território mais demarcado, definindo inclusive quais grupos de pares uma criança pertencente a um determinado hã terá convívio cotidiano ${ }^{13}$

As brincadeiras nos conectam, assim como as crianças, com a história do lugar, às histórias dos seus pais e avós, às pessoas anônimas que deixaram para as gerações futuras este patrimônio. Sobre este aspecto, importante são as contribuições que nos trazem Tim Ingold e sua perspectiva ecológica de cultura. Para o autor, o conhecimento depende fundamentalmente da imersão dos sujeitos na tessitura dos fenômenos do mundo. Seu argumento vai no sentido de afirmar que o conhecimento consiste, em primeiro lugar, em habilidades, que são adquiridas na prática e não em informações que são passadas de geração à geração através de representações mentais. Assim, “...a contribuição dada por cada geração às suas sucessoras se revela como uma educação da atenção" (INGOLD, 2010, p. 19). O autor nos apresenta uma forte relação entre as pessoas, o ambiente e os processos de "embodiment", ou seja, da incorporação dos conhecimentos transmitidos. Neste sentido, podemos afirmar que as brincadeiras poderiam se

\footnotetext{
${ }^{13}$ Um hã é o grupo de parentes da mãe que convivem juntos dado a organização matrilocal, ou seja, quando ocorre o casamento, o marido vai morar junto à família da esposa, convivendo com seus parentes, irmãos, sogro, sogra, sobrinhos. Desta forma, um hã é formado por um casal de fundadores mais velhos, suas filhas e genros. Entre os habitantes do hã há interdição sexual, que se estende às crianças primas matrilaterais, que igualmente se consideram como irmãs. $\mathrm{O}$ hã tem grande importância para a sociabilidade infantil das crianças Galibi-Marworno. No espaço delimitado de seu hã, as crianças convivem com seus irmãos e primos matrilaterais e essas crianças e estes grupos de convivência são muito bem definidos, verdadeiras "repúblicas infantis". A autora analisa as relações de respeito e não respeito entre as crianças de um mesmo hã e de hãs diferentes que não possuem relação de parentesco. As crianças constroem uma noção de parentesco e atribuem às crianças não aparentadas como "aqueles em quem se pode bater ou de quem se pode apanhar" (CODONHO, 2007, p. 79).
} 
caracterizar como uma forma de transmissão de conhecimentos. É na paisagem, constituída pelos traços que lhe foram imprimindo aqueles que a habitaram anteriormente e que a habitam no momento, que o conhecimento pode ser acessado. Ou seja, o conhecimento não se processa "dentro de um sacrário mental interior, protegido das múltiplas esferas da vida prática, mas em um mundo real de pessoas, objetos e relacionamentos" (INGOLD, 2010, p.19). Nesta perspectiva, a idéia de aprender seria caracterizada por um processo que consistiria em estabelecer uma sintonia fina e uma sensibilização de todo nosso sistema perceptivo (mobilizando cérebro, os órgãos corporais periféricos, conexões neurais e músculos) com o ambiente e com os aspectos específicos que situam o sujeito no mundo. Por este motivo, chamamos a atenção para a forte relação que as crianças do campo estabelecem ao brincarem com seus respectivos ambientes de vida. Podemos exemplificar esta tese a partir da análise de alguns estudos produzidos sobre as infâncias de crianças do campo, reunidas em trabalhos como o de Gonçalves (2013) ${ }^{14}$ e o de Silva et al (2013).

Como exemplos desses estudos destaca-se o artigo de Pasuch e Moraes (2013) que trata de compor retratos sociológicos das infâncias vividas pelas crianças de assentamentos no estado de Mato Grosso. Quando as crianças foram solicitadas a darem seus depoimentos sobre como definiriam suas próprias infâncias, a presença das brincadeiras em meio aos elementos da natureza se destacam em seus discursos: andar a cavalo, banhos de rio, pescar, brincar de casinha, esconde-esconde.

Assim como o brincar, atividades como ir a escola e trabalhar (sobretudo junto ao seu grupo familiar como carpir, cuidar dos animais e dos irmãos menores) estão também presentes em seus cotidianos. Na realidade, não se sabe ao certo se na conjugação de forças qual seria o peso dado a estas três atividades na vida destas

\footnotetext{
${ }^{14}$ Em levantamento realizado junto a base de dados da capes, a base de artigos da Scielo e os grupos de trabalho da ANPED buscando constituir um estado da arte sobre as pesquisas que têm como objeto de estudo a Educação Infantil do campo, Gonçalves(2013) identificou 15 produções (2002-2012 classificadas pela autora por concentrar seu foco sobre a educação, cultura e infância em contextos de comunidades do campo. Analisou-se o modo como as comunidades rurais, de diferentes contextos- comunidades indígenas, ribeirinhas e zona rural- tratam da educação da infância do campo. Grande parte dos trabalhos analisados teve como base as situações lúdicas e de brincadeiras das crianças.
} 
crianças, mas é muito forte a ideia de definir a infância do campo como tempo de aprendizado do trabalho. Dizemos tratar de uma relação de poder porque em seus próprios depoimentos é clara a ideia de que o brincar possa ser subtraído de suas vidas em função de uma das outras atividades ${ }^{15}$.

infância pra mim é trabalhar de enxada, foice, roçar mais meu pai e minha mãe e... só! (Igor, 7 anos) [...] As vezes fico muito tempo no ônibus e quando chego em casa tenho serviço e chega a noite não dá mais pra brincar (Marcos, 7 anos) (PASUCH; MORAES, 2013, p. 82-83)

Outra pesquisa que relaciona o brincar e o ambiente busca analisar as experiências da infância entre crianças ribeirinhas da Amazônia, e seu papel de coconstrutora de conhecimento, identidade e cultura (TEIXEIRA; ALVES, 2008). Segundo as autoras as peculiaridades do modo de vida ribeirinho se constituem na “expressão mais tradicional e a que melhor retrata e conserva os valores da história cultural da Amazônia” (TEIXEIRA; ALVES, 2008, p. 2). Os ribeirinhos estão localizados no "interior", portanto fazem parte da cultura rural da Amazônia e é neste contexto que as autoras analisam a cultura infantil, através das brincadeiras.

Para elas a relação das brincadeiras com o contexto da comunidade ribeirinha se expressa no processo de construção de significados que ocorrem nos momentos de brincar. A beira do rio foi o local mais escolhido pelas crianças para brincar, característica marcante das crianças ribeirinhas. No estudo das brincadeiras deste grupo infantil, as brincadeiras mais presentes foram as de faz-de-conta, quando as crianças representavam as atividades domésticas como brincar de mamãe-filhinho, fazer comidinhas, lavar louças. A descrição desta última revela o ambiente como produtor de affordances para o brincar das crianças. Ao brincar de lavar as louças, as crianças levavam os utensílios até o rio, ou buscavam água no rio para lavá-los, costume e característica das famílias. Outras brincadeiras também fizeram parte do

\footnotetext{
${ }^{15}$ A idéia que se destaca acima de co-participação das crianças nas tarefas de seu grupo familiar, fossem elas voltadas para a produção de alimentos, manutenção da casa ou de geração de renda (venda de artesanato) é também uma característica presente em outros grupos do campo, como por exemplo, os indígenas (SILVA, 2014; MIRANDA, 2009) e as comunidades ribeirinhas (MEDAETS, 2011). Neste último caso, a autora reinvidica a ampliação da ideia de que a participação da criança de atividades produtivas seja vista unicamente como exploração, pois em certos casos como entre as crianças pataxó de Coroa Vermelha, esta ação das crianças desempenhavam papel fundamental nos processos de territorialização e no fortalecimento da identidade étnica e da cidadania Pataxó (MIRANDA, 2009 apud GONÇALVES, 2013, p.106)
} 
repertório das crianças: o pescador, o barqueiro, o coletor de açaí. Os transportes que apareciam nas brincadeiras eram as balsas, barcos e canoas, os mesmos utilizados pela comunidade. Da mesma forma, materiais utilizados por seus pais na extração do açaí também se fizeram presentes nas brincadeiras.

Em Mubarac Sobrinho (2008) a pesquisa analisa como através das brincadeiras as crianças da etnia indígena Sateré Mawé vivenciam momentos de (re)construção da cultura com os elementos que são incorporados da cultura dos "brancos". Por possuírem intenso contato com espaços urbanos e populações nãoindígenas, vemos em suas brincadeiras um reflexo de apropriação cultural, pois nelas estão presentes os rituais, músicas, valores e cultura do grupo indígena, como por exemplo, o ritual de "fazer a farinhada", que as crianças reproduzem ao brincar, mesclado às brincadeiras "urbanizadas", com brinquedos industrializados que algumas crianças possuem.

Do levantamento realizado por Gonçalves, algumas pesquisas relacionavam o brincar às narrativas e ao imaginário infantil das crianças do campo. Como a pesquisa desenvolvida por Silva Jr. (2011) com crianças em comunidades do Rio Trombetas, município de Oriximiná (PA), com a finalidade de perceber, analisar e registrar as expressões lúdicas das crianças nos espaços e formas por elas sugeridos. Como resultado obteve-se a descrição narrativa de várias expressões lúdicas ativadoras de representações do imaginário social peculiar amazônico e reveladoras de interações com a educação e seus processos de construção de conhecimentos nas comunidades ribeirinhas. Já Maritza Maldonado (2009), ao investigar as crianças da região Pantaneira afirma que a experiência da criança da Campina resiste ao saber e ao poder da experiência da infância na modernidade, experiência ímpar que, no seu limite, talvez, possa produzir algo novo, que seja diferente do sujeito individual requerido pelo projeto moderno (MALDONADO, 2009, s/p). Assim, a autora questiona como as crianças da Campina "burlam as regras do processo de subjetivação capitalístico, fazendo acontecer a experiência coletiva" (GONÇALVES, 2013, p.109). Em ambos os estudos verificamos a forte influência e dialogo das 
crianças com a cultura local e o ambiente natural envolvente servindo de referencia para seu brincar.

\section{considerações finais}

Os brinquedos e as brincadeiras como elementos constitutivos de um repertório cultural produzido na infância do campo instigam inúmeras interpretações e contribuem na construção de uma olhar sensível a essas crianças e seus modos de vida. A análise desse pequeno repertório instiga a compreensão do fenômeno da brincadeira marcado por elementos culturais e transmitido ou criado pelas crianças em seus espaços, tempos e interações, além de provocar uma reflexão de como, ao brincar, as crianças aprendem, desenvolvem e compreendem sistemas simbólicos fundamentais para sua participação na história e na cultura. Nesse sentido apontamos como desafios para as pesquisas com crianças do campo e suas culturas a necessidade de se relacionar a prática da brincadeira ao amplo imaginário da infância em contexto, como tão bem faz Romeu (2016) ao inventariar os brincares das crianças do Cariri em uma pesquisa etnoliterária que decalca os mitos, ritos, adivinhas corpos, invenções e sonhos das crianças.

Sugerimos aqui uma preocupação antropológica e histórica com o possível desaparecimento do repertório das chamadas "brincadeiras tradicionais" na contemporaneidade. Sua existência nos contextos do campo está, sem dúvida, ligada ao fato de as crianças, em muitos casos, pertencerem a grupos com traços identitários e culturais próprios que se distanciam em muitos aspectos da forma de organização social de, por exemplo, um grupo de crianças de classe média que vive em uma grande cidade.

Defendemos aqui, ao pensarmos em processos educativos para a criança, a importância das brincadeiras tradicionais e da aproximação das infâncias do campo e da cidade, no sentido de promover um alargamento da experiência da infância de ambos os contextos, sobretudo das crianças de centros urbanos. Desta maneira nos colocamos contra uma forte tendência que marca a infância das crianças urbanas e que promove sua institucionalização, decorrente de processos gerados pela sua hiper-escolarização, pela sensível redução de espaços para a prática de brincadeiras, 
pela vigilância e controle exercidos pelos adultos (transmutados muitas vezes sob o discurso da proteção), que inibem a circulação e o convívio das crianças com seus pares.

Em outra lente analítica não podemos nos furtar aqui ao desafio de rompermos com uma visão idealizada da infância como período livre das asperezas do mundo, buscando uma análise crítica e apurada sobre a infância na qualidade de categoria social e dos impactos sociais que sofrem as crianças, atores sociais, em uma sociedade desigual. Nesse sentido, a escolha do tema da infância e brincadeiras ao tratar das crianças do campo não nos libera da realização de um contraste com uma realidade que em estudos de décadas anteriores apontaram que crianças desse grupo social viviam uma "falsa infância" ao destacar que elas ao se referirem a seus cotidianos sempre apontavam para um futuro e não para o presente, marcado pela violência e a exploração, expostas a brutalidade e a iniciação precoce ao trabalho (MARTINS, 1993). Apesar das várias iniciativas no campo das políticas públicas para reverter este quadro, ainda reproduz-se nos dias de hoje um cenário de uma sociedade adultocêntrica e de grande dívida histórica com as crianças (ROSEMBERG, 2013).

Fica portanto a lição crítica feita por Rosemberg (2013) que propõe que possamos nos desfazer das nossas idealizações ou de nossa visão idílica do campo e da própria imagem de infância que construímos. Como afirma a autora há que se mensurar a necessidade de foco nas metas de fortalecimento identitário, no plano simbólico, mas também em metas de justiça distributiva no plano material. Assim, essa população que teve historicamente no Brasil seus direitos sociais básicos tardiamente legitimados no âmbito legal ainda luta e reivindica direitos, dignidade e justiça ${ }^{16}$.

Por fim, outro elemento desafiador está na compreensão de que mesmo diante da diversidade de realidades dos chamados "povos do campo", esses diferentes grupos trazem em comum uma forte relação com a terra em que vivem.

\footnotetext{
16 O censo demográfico do IBGE (2010) 3,59 milhões de crianças residindo em área rural, 71\% das famílias viviam no quartil inferior a $R \$ 192,31$ mensais por morador. Além dos índices de pobreza continuarem altos e mais intensos entre crianças do que entre adultos.
} 
Esta relação se expressa a partir da delimitação de seus territórios ancestrais (por exemplo quilombolas ou indígenas), nos conhecimentos que estas populações dominam sobre os ecossistemas que habitam e no jeito de manejá-los de forma não predatória, produzindo seu sustento diário. Um trabalho inspirador nesse caminho é o de Piorski (2016), que inaugura uma série que explora a imaginação do brincar e sua intimidade com os quatro elementos da natureza. Ultrapassando uma visão meramente idílica e valendo-se da fenomenologia da imaginação material o trabalho estimula a escuta da criança e de sua imaginação por meio do que autor chama "voz livre da criança" e relaciona a experiência da brincadeira ao imaginário infantil.

Se é tão importante e necessária a ideia de associar as infâncias vividas pelas crianças ao território por elas ocupado, pode-se afirmar que deveria fazer parte de nossas análises o componente do território de vida destas crianças ${ }^{17}$. Desta forma, qual seria a relação que podemos estabelecer entre a infância das crianças e o território em que vivem suas dinâmicas sociais e os respectivos ambientes naturais que as envolvem? Que papel teria o ambiente na caracterização do brincar das crianças e na configuração das culturas infantis desses grupos?

Todas essas questões ficarão para futuros exercícios de pesquisa na clareza de que o movimento aqui iniciado é apenas uma aproximação do tema.

\section{referências}

AMADO, João. Universo dos brinquedos populares. Lisboa: Quarteto Editora, 2002.

BENEDICT, Ruth. O crisântemo e a espada. Padrões da cultura japonesa. São Paulo: Perspectiva, 2007.

BRANDÃO. Educação como cultura. São Paulo: Mercado das Letras. 2002

BROUGÈRE, G. A criança e a cultura lúdica. Revista da Faculdade de Educação da USP. v. 24, n. 2, São Paulo, p. 103-116, jul./dez. 1998.

CARVAlHO, A. M. A.; MAGAlHÃES, C. M. C.; PONTES, F. A. R.; BICHARA, I. D. (Ed.). Brincadeira e cultura: Viajando pelo Brasil que brinca. São Paulo: Casa do Psicólogo, 2003.

CARVALHO, Levindo Diniz. Imagens da Infância: brinquedo, brincadeira e cultura. Dissertação de Mestrado. Faculdade de Educação - UFMG, 2005.

${ }_{17}$ Podemos pensar no seu contrário, ou seja, na ausência deste território e o impacto que causa sobre estas populações. O que poderíamos dizer por exemplo, da infância vivida por crianças de grupos que vivem situações de extrema disrupção em seus territórios como perda, invasão ou degradação (como o caso de muitas populações indígenas dentre elas os Guarani-Kaiwoá do Mato Grosso do Sul, ou das crianças dos diversos assentamentos pelo país do Movimento Sem Terra)? 
CASCUDO, Luiz da Câmara. Dicionário do Folclore Brasileiro. Belo Horizonte: Itatiaia: São Paulo: Editora da Universidade de São Paulo, 1988.

CODONHO, Camila Guedes. Aprendendo entre pares: a transmissão horizontal de saberes entre as crianças indígenas Galibi-Marworno, Florianópolis, SC, UFSC. Dissertação de mestrado em antropologia, 2007.

CUNHA, Manuela Carneiro da. Cultura com aspas: e outros ensaios. São Paulo: Cosac Naify, 2009.

FERNANDES, Florestan. As Trocinhas do Bom Retiro. Folclore e mudança social na cidade de São Paulo. Proposições, v 15, n. 1 (43) jan/abr, 2004.

FRIEDMANN, Adriana. Jogos tradicionais na cidade de São Paulo: recuperação e análise da sua função educacional. 1990. Tese (Mestrado em educação.) -Universidade de São Paulo, São Paulo, 1990.

GONÇALVES, Raphaela D. F. S. O estado da arte da infância e da Educação Infantil do campo: debates históricos e construções atuais. 2013. Dissertação (mestrado em Educação). Universidade Estadual de Feira de Santana.

HUIZINGA, Johan. Homo ludens: o jogo como elemento da cultura. São Paulo: Perspectiva, 2014.

INGOLD, T. Da transmissão das representações a educação da atenção. Educação: Porto Alegre, v. 33, n. 1, p. 6-25, jan./abr. 2010.

KISHIMOTO, T. M. Jogo, brinquedo, brincadeira e educação. 3. ed. São Paulo: Cortez, 1999.

KISHIMOTO, T. M. Jogos tradicionais infantis. São Paulo: Cortez, 1996.

MALDONADO, Maritza Maciel Castrillon. Espaço Pantaneiro: cenário de subjetivação da criança ribeirinha. Doutorado. Rio de Janeiro: Universidade Federal Fluminense. 2009.

MARTINS, José de Souza (coord.). O massacre dos inocentes: a criança sem infância no Brasil. 2. ed. São Paulo: Hucitec, 1993.

MEAD, Margaret. Coming of Age in Samoa. New York: William Morrow, 1928.

MELO, Veríssimo de. Folclore infantil. Belo Horizonte: Editora Itatiaia, 1985.

MIRANDA, Nicanor. 200 jogos infantis. Belo Horizonte: Editora Itatiaia, 1984.

MURABAC SOBRINHO, Roberto Sanches. "Pra fazer a farinhada... muita gente eu vou chamar": contextos lúdicos diversificados e as culturas das crianças Sateré-Mawé. $31^{\text {a }}$ Reunião Anual da ANPEd. Caxambu/MG, 2008.

NUNES, Ângela. A Sociedade das Crianças A'uwêe-Xavante - por uma antropologia da criança. Lisboa: Instituto de Inovação Educacional/Ministério da Educação, 1999.

PASUCH, Jaqueline; MORAES, Eulene V. Retratos sociológicos das infâncias do campo. In: SILVA, Isabel de Oliveira; SILVA, Ana Paula Soares da; MARTINS, Aracy A. (orgs.) Infâncias do Campo. Belo horizonte: Autêntica, 2013. p. 77-89.

PIORSKI, Gandhy. Brinquedos do chão: A natureza, o imaginário e o brincar. São Paulo:

Periópolis, 2016.

ROMEU, Gabriela. Terra de Cabinha: pequeno inventário da vida de meninos e meninas no sertão. São Paulo: Periópolis, 2016. 96 p.

ROSEMBERG, Fúlvia. Narrativas adultas sobre lugares de vida de crianças brasileiras: infâncias do campo. In: SILVA, Isabel de Oliveira; SILVA, Ana Paula Soares da; MARTINS, Aracy A. (orgs.) Infâncias do Campo. Belo horizonte: Editora Autêntica, 2013. p.247-278.

SILVA JUNIOR, Adélcio Correa da. Rio Abaixo, rio acima: o imaginário amazônico nas expressões lúdicas de crianças ribeirinhas. Mestrado. Belém: Universidade do Estado do Pará. 2011.

SILVA, Lúcia Isabel da Conceição. Papagaio, pira, peteca e coisas dos gêneros. 2006. Tese (Doutorado em Educação) - Faculdade de Educação, Universidade Federal do Pará, Belém/Pará, 2006. 
infâncias no campo: brinquedo, brincadeira e cultura

SILVA, Isabel de Oliveira; SILVA, Ana Paula Soares da; MARTINS, Aracy A. (orgs.) Infâncias do Campo. Belo horizonte: Editora Autêntica, 2013.

SILVA, Rogério Correia da. Participação e aprendizagem na educação da criança indígena. Revista Brasileira de Educação, v. 19, n. 58, jul-set. 2014. p 655-670.

TEIXEIRA, Sônia Regina dos Santos; ALVES, José Moysés. O contexto das brincadeiras das crianças ribeirinhas da Ilha de Combu. Revista Psicologia: reflexão e crítica. v.21, n.03, Porto Alegre, 2008.

recebido em: 26.09 .2017 aceito em: 30.11 .2017 